\title{
EL ORIGEN DEPORTIVO DE LA DEMOCRACIA: UNA APROXIMACIÓN FILOSÓFICA
}

\author{
A ORIGEM ESPORTIVA DA DEMOCRACIA: UMA ABORDAGEM FILOSÓFICA
}

THE ORIGIN OF DEMOCRACY IN SPORTS: A PHILOSOPHICAL APPROACH

Francisco Javier Lopez Frías ${ }^{*}$ Emanuele Isidori ${ }^{* *}$

Palabras clave:

Filosofía del deporte.

Pedagogía.

Educación.

Democracia.
Resumen: Este artículo afirma, desde un punto de vista hermenéutico, que el deporte puede ser una importante herramienta educativa para nuestras sociedades democrático liberales. Para justificar esta afirmación, primero analizamos la polémica cuestión de si el deporte es una actividad seria que está ligada a la sociedad y sus valores. En segundo lugar, afirmamos que el deporte siempre ha sido una actividad ligada a la sociedad, desde la Antigüedad. En tercer lugar, mostramos que tanto el origen de la política como el de la filosofía estuvieron ligados a ciertas fuerzas y actitudes relacionadas al deporte. En cuarto, exponemos cómo estas fuerzas aún son centrales para el deporte contemporáneo. Como conclusión, defendemos la tesis de que podemos utilizar el deporte para mejorar la calidad de nuestras sociedades democrático liberales. Filosofia do esporte. Pedagogia. Educação. Democracia
Palavras chave:

Resumo: Este artigo afirma, do ponto de vista hermenêutico, que o esporte pode ser uma importante ferramenta educacional para as nossas sociedades democrático-liberais. Para demostrar essa afirmação, em primeiro lugar analisamos a questão controversa sobre se o esporte é uma atividade séria relacionada à sociedade e aos seus valores. Em segundo lugar, afirmamos que o esporte foi sempre uma atividade ligada à sociedade desde os tempos antigos. Em terceiro lugar, mostramos que tanto a origem da política quanto a da filosofia estiveram vinculadas a certas forças e atitudes relacionadas ao esporte. Em quarto, expomos como essas forças ainda são centrais para o esporte contemporâneo. Em conclusão, apoiamos a tese de que podemos usar o esporte para melhorar a qualidade de nossas sociedades democrático-liberais.

Abstract: This paper takes a hermeneutical perspective to argue that sport is a

\section{Keywords:}

Philosophy of sports.

Pedagogy.

Education.

Democracy. useful pedagogical tool for liberal-democratic societies. To do so, we first look into the controversial issue of whether sport is a serious activity linked to the larger society and its values. Second, we argue that sports have been closely connected to serious societal aspects since ancient times. Third, we relate the origins of both politics and philosophy to several forces and attitudes. Fourth, we show that such forces and attitudes are still at the core of contemporary sports. In conclusion, we advocate that sports can be used to improve liberal-democratic societies.
*Pennsylvania State University. Pennsylvania, USA. E-mail: fjl13@psu.edu

**Università di Roma Foro Italico. Roma, Italia.

E-mail: labopedagogia@gmail.com

Recebido em: 20-12-2017 Aprovado em: 27-04-2018

DOI: http://dx.doi.org/10.22456/1982-8918.78461 (c) (1) 은 Licence 


\section{INTRODUCCIÓN. LO SERIO Y LO LÚDICO, UN RETO PARA LA FUNCIÓN EDUCATIVA DEL DEPORTE}

Las preguntas que dieron origen a la filosofía del deporte tienen que ver con dos problemas íntimamente relacionados. Primero, la cuestión relativa al carácter serio o lúdico del deporte. Segundo, la relación que los valores de éste tienen con el total de la sociedad. Ya en 1939, el historiador Johan Huizinga (2005), trató ambos problemas en Homo ludens. En éste, se afirma que la naturaleza infantil, en tanto que extremadamente lúdica, del deporte le obliga a constituirse como una realidad totalmente aislada de la sociedad en que se inserta. Es decir, el deporte es una actividad trivial. No obstante, el carácter esencialmente lúdico-trivial del deporte, para Huizinga (2005), no excluiría la posibilidad de que sus valores tengan influencia en la sociedad.

Según el historiador holandés, toda cultura posee elementos lúdicos que influyen sus interpretaciones de la vida y del mundo (LÓPEZ FRÍAS; GIMENO MONFORT, 2016). De este modo, en muchas culturas antiguas la distinción entre los ámbitos de lo lúdico y de lo serio no estaba nada clara. Por ejemplo, los griegos trataron de distinguir entre agon y paidiá. Este último se refería al jugar en el sentido más infantil, el cual no tendría ningún lazo con la realidad social. Por su parte, el agon se empleaba en relación a la competición deportiva (entre otras competiciones de muy diverso tipo, como más tarde analizaremos). Sin embargo, advierte Huzinga, los límites que conformaban esta distinción nunca fueron fijos. Platón utilizó el término paidiá para los actos religiosos, los cuales no pueden concebirse de ninguna manera como una actividad infantil. Otra muestra más de los límites difusos entre lo lúdico y lo serio en la antigua civilización griega se encuentra en la íntima relación que existía entre los términos agon y agonía.

Siguiendo la función generadora de sentido (es decir, "seria") otorgada por los griegos a lo lúdico, Huizinga (2005) se pregunta si la conexión entre lo lúdico y lo serio aún permanece en nuestra sociedad. La respuesta que ofrece es negativa: pues afirma que el proceso por el que el deporte se ha convertido, desde el S.xIx, en un sistema profesionalizado y especializado ha desprovisto a éste de su carácter eminentemente lúdico. Aquello que acontece en el deporte moderno no tiene nunca más la capacidad de generar sentido que el agon poseía. Así, utilizando una terminología similar a la aportada por el sociólogo Max Weber, se puede afirmar con Huizinga que el deporte se ha desencantado, perdiendo su conexión orgánica con la sociedad.

Siguiendo el análisis de Huizinga, el S.xIx vio surgir una corriente pedagógica llamada la muscular christianity que defendió la necesidad de introducir el deporte en el currículum escolar con el fin de enseñar valores. Éstos no sólo serían útiles para el individuo (como el cuidado del cuerpo), sino también para la sociedad en general. En esta escuela de pensamiento se formó el Barón Pierre De Coubertin. Y es también aquélla en la que se origina la pedagogía del deporte de la que más tarde, en torno a los años 70 del siglo pasado, se desprendería la filosofía del deporte.

La filosofía del deporte, como hija y heredera de la pedagogía del deporte, convirtió en una de sus preguntas principales aquella referida a la función generadora de sentido, valores y principios internos del deporte. Así, desde el nacimiento de dicha disciplina, la mayoría de los filósofos del deporte, en tanto que defensores del deporte moderno, se han ocupado de repensar, y en muchas ocasiones refutar, la tesis presentada por Huizinga. Para muchos de ellos, como 
Paul Weiss (1969), el valor educativo del deporte se mantiene a día de hoy, pues éste es, sin duda, el lugar en el que los individuos tienen su primera toma de contacto con excelencias y habilidades propias del mundo adulto. Así pues, la filosofía del deporte, excluyendo algunas excepciones, se ha esforzado por demostrar, primero, que el deporte no es trivial y, segundo, que éste tiene mucho que decir en nuestra sociedad. No obstante, como bien han señalado Mike McNamee (1998) y R. Scott Kretchmar (2007), la orientación filosófica de los autores que han realizado estos intentos ha provenido siempre de la filosofía anglo-americana, cuya naturaleza es analítica o utilitarista. El abuso de la metodología analítica, según Kretchmar, (2007) ha conducido a la filosofía del deporte a alcanzar "puntos muertos" en lo que respecta a algunas de sus principales problemáticas. Este artículo propone que la solución a la parálisis en que se encuentra este debate puede encontrarse complementando la filosofía del deporte eminentemente analítica, con metodologías y propuestas filosófica continentales, en concreto, la filosofía hermenéutica.

\section{FILOSOFÍA HERMENÉUTICA DEL DEPORTE}

Puede decirse que la filosofía hermenéutica ha estado presente en la filosofía del deporte desde muy temprano, pues la corriente más extendida dentro de ella: el interpretacionismo, nació a raíz de la recepción que autores como Robert L. Simon (2000) o John S. Russell (1999) hicieron del pensamiento de Alasdair Maclntyre y Ronald Dworkin. Así, por ejemplo, desde la publicación de Tras la virtud, muchos autores han tomado el concepto de "práctica social" defendido por Maclntyre con el fin de describir el deporte. De este modo, la tarea de la filosofía del deporte sería la de desentrañar cuáles son esos bienes internos, valores, y excelencias propias del deporte.

A pesar de poseer un origen hermenéutico, muy pocos filósofos del deporte han llevado a cabo verdaderos análisis hermenéuticos. El interpretacionismo, como defiende William J. Morgan (2012), ha reducido la tarea hermenéutica a la posibilidad de alcanzar un único principio general a la luz del que comprender la integridad del deporte. Este principio es aquel que, siguiendo la propuesta de Simon (2010), comprende el deporte como una búsqueda incesable de la excelencia. Como mostró Gadamer en su crítica a Dilthey y Schleiermacher, la hermenéutica no pretende reducir la complejidad de la realidad a un principio desde el que interpretarla. Su objetivo, más bien, es captar el sentido global de la misma, para lo cual se requiere mucho más que un simple principio interpretativo. Por ejemplo, hace falta recurrir a la tradición, a su relación con el resto de prácticas sociales, en definitiva, a todo aquello que "está siempre ahí influyendo sobre ella".

La aplicación de la metodología hermenéutica al estudio del deporte tiene que ver, principalmente, con el concepto de "prueba" entendido más allá de la referencia a sí mismo, es decir, como parte de ese "gran texto" que conforma el total de nuestra vida social (ISIDORI, 2011, p. 95). Así, las preguntas fundamentales que debe responder una filosofía del deporte construida en clave hermenéutica serían:

[¿Q]ué implicaciones comunitarias, sociales, políticas, éticos y educativas presenta el deporte en tanto que práctica cultural y humana? ¿Puede pensarse en el deporte al margen de una ética de la responsabilidad? ¿Cómo es posible repensar el deporte más allá de las posiciones que se dan por sentado, así como de los prejuicios y estereotipos que lo caracterizan, con 
el fin de convertirlo en una práctica humana respetuosa con la equidad, la justicia, la igualdad y los derechos de las minorías y las personas diferentes que deben ser reconocidas y aceptadas por la sociedad? ¿Cómo se puede convertir el deporte en un instrumento de cambio y transformación para el bien de la sociedad? (ISIDORI, 2011, p.96).

Si estas son las preguntas que caracterizan al método hermenéutico, puede afirmarse que la filosofía del deporte tuvo su origen en preguntas típicamente hermenéuticas, y no analíticas. Lo primero que ocupó y preocupó a los filósofos del deporte fueron las preguntas de ámbito práctico relacionadas con el sentido humano y social del deporte. Las cuales tratan de situar esta práctica en el total de nuestra vida, que es lo que al fin y al cabo nos preocupa de verdad. Dada esta preocupación vital de la que surge el preguntar, ¿cabe proponer que la filosofía, la política y el deporte griegos tienen un origen en común?

\section{EL DEPORTE COMO RESPUESTA A UNA PREGUNTA PARA LA RESOLUCIÓN DE CONFLICTOS: RELIGIÓN, PAZ, Y FILOSOFÍA}

Heather L. Reid ha mostrado que el deporte pudo servir de inspiración e, incluso, impulso para el surgimiento de la filosofía (REID, 2011; TUNCEL, 2013). La filósofa norteamericana justifica esta afirmación apelando a la función sacrificial que tenían los festivales deportivos griegos (esa misma función en la que Adorno y Horkheimer ya encontraron muestras del carácter dialéctico de la llustración). Todo festival tenía la función de ofrecer bienes a los dioses en señal de gratitud en espera de futuros bienes por venir. Es decir, se establecía una especie de relación mercantil entre los dioses y los humanos por la que los primeros compraban los favores de los seres superiores a través de los mejores sacrificios posibles. En esta relación "mercantil" era completamente necesario conocer las preferencias de los dioses, "meterse en su mente": ¿ No es este intento de conocer mejor a la divinidad, el principio de todas las cosas (arjé), aquel a partir del que nació la filosofía presocrática? ¿Qué podían querer los dioses de los atletas? ¿Qué ofrenda les entregaba el deporte?

Reid (2011) afirma que, como rito sacrificial, el deporte no ofrecía bienes materiales, sino a la persona más excelente. Por ejemplo, en los juegos celebrados en Olimpia, el vencedor de la carrera a pie era el encargado de encender la llama del templo de Zeus ("la llama del sacrificio"). El atleta, de este modo, era considerado como la ofrenda a los dioses (REID, 2011, p.22-32). Esta excelencia no tenía sólo que ver con la victoria, sino también con la humildad, el respeto mostrado hacia los otros y las reglas (como medidores imparciales de su rendimiento) y su actuación pública. Humildad, imparcialidad y publicidad son claves para el buen filosofar en la antigua Grecia, pues éste tenía lugar frente a otros en el ámbito público. Así, a juicio de la filósofa del deporte norteamericana, se produce el paso del agón deportivo (realizado en clave física), al agón filosófico (de naturaleza intelectual).

Como ha mostrado el historiador y arqueólogo Stephen G. Miller, el deporte no sólo tenía un valor sacrificial, sino también una función ética y social para la gestión de conflictos (MILLER, 2004). El deporte griego era un mecanismo generador de sentido, al modo de la religión, que influía en el comportamiento de los individuos. Su objetivo social era el logro de la cohabitación pacíica de un mismo espacio. Así, por ejemplo, durante los juegos olímpicos, los griegos eran llevados y reunidos en un mismo lugar, de tal modo que, en principio, las rivalidades políticas eran olvidadas y los lazos entre los griegos fortalecidos. Los juegos eran, pues, un medio para 
promover el entendimiento inter-comunitario entre las diversas comunidades griegas (MILLER, 2004). Por ello, un valor como el de la hospitalidad tomó un papel central en la celebración de los juegos.

\section{DEPORTE Y ÉTICA DE LA HOSPITALIDAD}

El deporte antiguo tenia conexiones con los ritos de la hospitalidad, de la acogida, de la paz, de la casa, de la comunicación entre diversos y extranjeros (los intercambios de xénia, - regalos - entre extranjeros de las diversas poleis durante los juegos son una prueba que confirma este concepto). Como ya hemos afirmado, todos los deportistas se reunían conjuntamente en una misma ciudad, Eléa, (MILLER, 2003, p.5-10) con el fin de entrenar, seguir sus dietas, mostrar sus habilidades, ser seleccionados para las pruebas definitivas, y ser arengados en las leyes de la ciudad por los "jueces de la ley" (hellanodikai). Los atletas llevaban con ellos a sus familiares, seres cercanos, y entrenadores, de modo que la ciudad que celebraba el festival deportivo debía acogerles. Este es un primer sentido en que la hospitalidad estaba esencialmente ligada al evento deportivo griego.

Pero no debemos olvidar que esta relación de acogida es recíproca, aquí el papel de los jueces de la ley se torna central, pues al igual que la ciudad tenía la responsabilidad de acoger a los deportistas, ellos tenían la obligación de cumplir con las normas de acogida de su nueva casa. Los jueces eran aquellos que, como ya hemos afirmado, trataban de inculcar esta obligación en los atletas. Estos hellanodikai tenían la función de convertir el entrenamiento y el esfuerzo físico en las reglas principales de la casa. Así, en la procesión desde Elea hasta Olimpia obligaban a los atletas a realizar el siguiente juramento: "Si has trabajado como para ser merecedor de ir a Olimpia, si no has hecho nada indolente o innoble, entonces animaos y marchad; pero aquellos que no han entrenado de este modo podéis marcharos $e$ ir donde queráis" (MILLER, 2003, p.9)

Sólo aquellos que se han comportado como requiere la "casa" son los merecedores de ir a Olimpia. En este sentido, el deporte siempre ha estado en conexión con la ética en el sentido literal de la palabra: "ética" - desde la palabra griega êthos -, que significa no solo "costumbre", sino también "casa" o también "manera de comportarse en su propia casa". Así, para los griegos antiguos, la ética era un problema de relación "cara a cara", un problema de cómo respetar las leyes religiosas y sociales y acoger a los extranjeros - que expresaban y sintetizaban en sus caras a los dioses y a la comunidad humana. De hecho, en el frontal del templo de Zeus en Olimpia se ve a Apolo, dios de la razón y del orden del mundo, resolver la controversia entre los centauros y los lapitas. Un problema que fue, esencialmente, una cuestión de mal comportamiento en la casa.

Cuenta la historia que durante la boda entre Pirítoo e Hipodamía, los centauros, que eran parientes de la novia, motivo por el que estaban invitados al evento, intentaron violarla. Con ello, evidentemente, atentaron contra las reglas de la casa de acogida y, por lo tanto, de la hospitalidad. De este modo, el mito fundador de Olimpia, la ciudad deportiva por excelencia, es un mito ético en el sentido de "un mito de la casa", de la hospitalidad, de la acogida de la diversidad, y del saberse comportar según las reglas de la casa. Esto muestra que Olimpia, y por extensión el deporte, estuvieron desde un principio esencialmente vinculados a la acogida y la hospitalidad del otro. 
Dado este sentido profundamente "hospitalario" del deporte, éste poseía, evidentemente, una dimensión social y política; una innegable conexión con la polis, la ciudad, su gobierno y su vida cotidiana. ¿Pueden, entonces, establecerse (al igual que hicimos con la filosofía) lazos entre el origen y la actitud del deporte y los de la política griega? Aquí defenderemos que sí, pues los griegos fueron los inventores no solo del deporte, sino también de la política, que era para ellos, precisamente, el arte supremo del cuidarse de las cosas de esa gran casa que era la ciudad (la polis).

\section{EL DEPORTE Y LA POLIS}

Como muestra David J. Philips (2003), el deporte griego siempre estuvo esencialmente ligado a la política. Los Juegos eran, en principio, una celebración de la unidad y de la nodiferencia entre las polis, más allá de la establecida por las habilidades física. No obstante, también eran una competición individualizada entre las diversas ciudades-estado no solo por ganar y mostrar la superioridad física de sus poblaciones, sino también a la hora de mostrar la grandeza de sus ciudades. Así, Philips (2003) cita los trabajos de Jennifer Neils (1992) sobre los eventos deportivos griegos. En ellos, ésta recoge lo que suponía para una ciudad como Atenas el hecho de organizar un evento deportivo:

[S]u sentido de la integración, ejemplificando la democracia participativa de la ciudad, en estas competiciones se demostraba en el espíritu competitivo de sus gentes, con sus premios mostraba las habilidades de sus artesanos y la riqueza de sus productos; y sobre todo, celebraba a Atenea como la divina protectora de una ciudad gloriosa (NEILS, 1992, p. 27, apud PHILIPS, 2003, p.202).

Así, organizar los juegos y hospedar a los extraños no era solo una cuestión de "hospitalidad", sino también de poder político y de competición entre las ciudades. Esta competición se observa de forma más clara aún en el hecho de que muchas ciudades daban la ciudadanía a habitantes de otras ciudades en base a sus habilidades deportivas con el fin de formar grupos de atletas más competitivos. No era solo cuestión de dar ciudadanía, sino llenarles de honores y bienes como comida gratis y exenciones de impuestos (así como de otros servicios comunitarios). Por otra parte, otros gobernantes utilizaron el prestigio logrado a través del deporte para prolongar y extender su poder, así por ejemplo, Philips (2003) afirma que el caso más claro de este tipo de gobernantes fue Filipo II de Macedonia, que postulándose como defensor del ideal olímpico alcanzó una fama que le permitió adquirir aliados y poder a través de la utilización de los eventos deportivos (MILLER, 2004).

Por lo tanto, podemos afirmar que en el mundo antiguo, el deporte fue, también, una cuestión ligada al ámbito de lo político: a la ciudadanía (sólo los hombres libres, los griegos que habían demostrado su ciudadanía y su puro origen griego, por ejemplo, podían participar en los sagrados Juegos Olímpicos), a la ideología (demostración de la fuerza personal frente a los miembros de su propia comunidad) y al poder (capacidad para obtener papeles de mando demostrando ser excelentes atletas y, con ello, excelentes ciudadanos). Una ligazón que, con sólo prestar atención a la historia de nuestro deporte moderno, parece mantenerse también en el deporte contemporáneo.

La historia de los Juegos Olímpicos está plagada de ejemplos de uso político de los mismos. Desde las Olimpíadas Nazis de 1936 en Berlín, hasta los boicots realizados a las Olimpiadas de 1980 (Moscú) y 1984 (Los Ángeles). No obstante, este ensayo pretende 
ir más allá de los hechos históricos, y alcanzar lo que dentro de la hermenéutica se suele denominar como hecho "factico" o "facticidad". Así, más allá de los hechos concretos que muestra la conexión entre política y deporte, trataremos de encontrar aquí una ligazón "más hermenéutica", es decir, vinculada al sentido mismo de la práctica deportiva que, a nuestro juicio, puede encontrarse en el concepto de "agón".

\section{DEPORTE, AGÓN Y DEMOCRACIA. UN ANÁLISIS HERMENÉUTICO}

No hemos de olvidarnos de que los Juegos Olímpicos empezaron oficialmente en el año 772 a. C. La filosofía nació en Grecia en el S. vi-v a.C. y la democracia se desarrolló en Atenas en el S. v a. C. Por esta razón, y tal como hemos mostrado en los apartados anteriores, podemos decir que el deporte es más antiguo que la filosofía y la democracia y, por lo tanto, puede ser que conceptos fundamentales que se encuentran tanto en la filosofía, como en la democracia provengan del deporte. La conexión entre deporte, política, y democracia se muestra de forma evidente en el concepto de "agón", que representa el sentido mismo del deporte antiguo y, también, del deporte olímpico.

Agón posee la raíz "“ag-", que se encuentra en la palabra griega "agorà", es decir, "la plaza”, el lugar por excelencia de la vida política, comunitaria, económica, religiosa - pero, sobre todo, democrática - de la ciudad antigua. Hemos de ser conscientes de que el deporte siempre se refiere a cuestiones sobre la agorà. Por ello, afirmamos que este concepto de agón se encuentra en la raíz de las principales influencias del deporte sobre la filosofía y la democracia. A día de hoy, este agorà se ha convertido no solo en un espacio social y cultural planetario, sino en el mercado del mundo global y globalizado. Así, no siempre es fácil para el filósofo proporcionar una lectura del deporte teniendo en cuenta este complejo escenario multifacético, histórico, inacabado y en constante cambio. No obstante, éste debe saber siempre que la interpretación que se da del deporte tiene un componente "político" de forma implícita. Este "implícito" debe siempre tenerse en cuenta, ya que surge de manera más o menos explícita en relación con los componentes social, pedagógico, ético y moral, histórico, económico y jurídico del deporte.

Los antiguos héroes homéricos formaban un círculo cuando tenían que hablar, enfrentarse, compartir premios y recompensas, discutir, luchar, competir, dialogar, pronunciar opiniones, evaluar y juzgar, hablar para decidir, actuar, proyectar, desarrollar estrategias, ser jefes. En este círculo eran todos iguales, se miraban cara a cara, se reconocían como seres humanos, sin miedo el uno del otro; eran todos homoioi, hablaban la misma lengua, se entendían y reconocían recíprocamente. Al modo de una hermenéutica dialógica de la comprensión-interpretación, ninguno se situaba como jefe absoluto, sino simplemente como jefe, como princeps inter pares, y siempre y cuando éste demostrara ser el mejor entre otros iguales. Así, era dentro de este círculo dónde los guerreros homéricos tenían que demostrar su valor personal (y tal vez físico-atlético) y merecer así el mando del grupo; un mando que implicaba siempre un compromiso y una responsabilidad frente al grupo.

Este círculo público de guerreros era el agón. Sabemos que la democracia y la filosofía tienen un origen agonal porque se basan en el debate, la confrontación, el diálogo para la persuasión, que son posibles gracias a que los miembros de ese círculo comparten un discurso y los principios del mismo (el logos). El agon es también el grupo de personas que se reúne 
para escuchar un discurso (la defensa en frente de un juez, una arenga política, leen un libro) o ver una competición (debate entre político o una acalorada discusión filosófica) llevados a cabo según unas reglas compartidas y establecidas públicamente. De este modo, tanto la filosofía, como la democracia, la máxima expresión del pensamiento político y de la ciencia social de los griegos, presentan una conexión visual con el círculo, con el agón de las antiguas competiciones que, por esto mismo, se llamaban agones.

Así, Miller (2004) sostiene que algunos de los principios de los antiguos agones deportivos (y olímpicos) han tenido influencia sobre algunos conceptos fundamentales de la filosofía y la democracia. En este sentido, la filósofa del deporte Claudia Pawlenka (2005) ha mostrado cómo el propio Rawls pensaba en las condiciones de igualdad que se dan en las competiciones deportivas mientras reflexionaba sobre los componentes que deberían dar forma a su concepción de la justicia. Veamos cuáles son estos principios que señala Miller 2004):

1) El primero es la isonomia, es decir, el concepto de igualdad ante la ley y las reglas a las que se someten los participantes en una competición. Todos los atletas son iguales; el mismo Miller, indica que el elemento que más de inmediato y de forma gráfica mostraba esta igualdad era la desnudez de sus cuerpos (MILLER, 2004). Competir desnudos significaba la cancelación de cualquier tipo de diferencias (de procedencia geográfica, de estatus económico y social, de etnia, etc.). La desnudez cancelaba las jerarquías y las diferencias sociales. Lo importante de esta cancelación de las diferencias (no debidas al entrenamiento) radicaba en que todos tuvieran la posibilidad de ganar en una competición: ricos y pobres, de Atenas o de Corinto, nobles y gente del pueblo, etc. De hecho, se dice que el primer ganador de los Juegos Olímpicos fue un cocinero, que nunca habría podido demostrar su areté por sangre, pero que demostró ser el mejor por medio de la areté atlética. Como ya afirmamos, todos los atletas realizaban un juramento mientras se entrenaban en Elea, se les inculcaban unas leyes comunes. De este modo, mientras se encontraban en Olimpia, los griegos, aunque provenían de diversas ciudades de la Grecia con leyes muy diferentes, podían ser juzgados por las mismas leyes y reglas (no sólo las deportivas).

2) El segundo principio, que se encuentra también en el léxico de la democracia, es la isegoría. Ésta se refiere al hecho de tener igualdad de acceso y participación a las competiciones (siempre y cuando se fuera un ciudadano griego). En la democracia ateniense, la isegoría consistía en el derecho de cada ciudadano para hablar públicamente frente al agorà, teniendo tanto la misma posibilidad de hablar, como igual dignidad entre iguales como ciudadano. Este concepto no era perfecto; mujeres, esclavos, extranjeros no podían participar. No obstante, sucede igual en la democracia hoy. Nos encontramos con un modelo que no es perfecto porque está en continuo desarrollo y adaptación. Lo cual no resta valor al concepto, pues se trata de una noción viviente y en continua evolución que necesita de un constante compromiso y una responsabilidad personal y comunitaria para su desarrollo.

3) El tercer principio es lo de la isokratía. Éste requiere tener el mismo poder (de participar tanto en las competiciones, como en la vida pública de la pólis) y la misma fuerza para ganar (y actuar como político en la ciudad) y demostrar no solo ser el mejor, sino el valor de uno mismo. La isokratía daba la posibilidad a todos los atletas (como en la democracia a los ciudadanos) de ganar las competiciones y, así, merecer el premio (que en la ciudad consistía en merecer ser el jefe y hacer cosas para su propia ciudad). Este es el verdadero 
sentido del concepto de poder, que adquiere el sentido del verbo latino "possum". Éste significa "tener la posibilidad de", es decir, en nuestro contexto se trata de poder actuar y ser tanto jefe, como guía honrado. Lo cual se ha ganada por el hecho de que se han respetado las reglas y aceptado la ética pública de su propio pueblo y Estado.

El deporte como agón expresa, por lo tanto, el concepto que es la raíz misma de la democracia: todos somos homoioi. El deporte como agón nos dice que somos (y tenemos la posibilidad de ser) libres. Nuestra libertad, tanto en el deporte como en la democracia, no es una libertad absoluta (que sería negativa): no podemos hacer todo lo que queremos porque esta libertad está vinculada a la libertad de los otros que, a su vez, están vinculados a nosotros. En la democracia, como en el deporte, todas las libertades de los participantes son libertades recíprocamente vinculadas que expresan intereses que son individuales y comunitarias al mismo tiempo.

El filósofo del deporte Mark Holowchak (2002) denuncia que dentro de este ámbito académico suele ser habitual que los diversos filósofos conciban el deporte como el lugar paradigmático de culminación de la libertad y la creatividad de los individuos, es decir, como el máximo exponente del individuo completamente libre moderno. Así, Miller W. Brown (1984), en relación al dopaje, ha defendido que poner cotas a este espacio de expresión puramente moderno a través de regulaciones que limiten dicha libertad y creatividad atenta no solo contra la autenticidad del deportista como sujeto plenamente libre, sino también contra la propia naturaleza plenamente moderna de la práctica deportiva. A juicio de Holowchak (2002), este tipo de propuestas olvidan ese otro lado comunitario, de co-responsabilidad que hemos tematizado aquí.

Nosotros, a través de este artículo, nos sumamos a la llamada de atención teórica de Holowchak (2002). Lo seres humanos siempre somos en relación a otros, somos en y con otros, no somos átomos dispersos totalmente autónomos o mónadas "sin puertas, ni ventanas" al estilo leibniziano. En el deporte, en el agón, tanto nosotros como los antiguos renunciamos a una parte, a una porción de nuestra libertad: esto lo hacemos en plena libertad, sin ninguna obligación externa. Los atletas en Olimpia escogían en absoluta libertad someterse a las reglas y a las leyes del agón, renunciando con ello a sus privilegios. Esto lo hacían (y los hacemos nosotros en la democracia) con el objetivo de obtener el reconocimiento de su mérito por parte de la comunidad, y con éste, el reconocimiento de un honor y un valor superiores a los individuales (los méritos comunitarios poseen un honor y un valor mayor que los individuales). El deportista moderno debe ser consciente de esta ligazón que lo hace responsable también ante los otros. Al igual que el sujeto moderno debe de serlo con respecto a esos otros que le rodean en la interacción social. Como ha defendido el filósofo francés Raymond Aron: "[...] someter la competición a reglas controladas por árbitros, ¿no es esa la imagen de la única reconciliación concebible entre las gentes que es compatible con la naturaleza de las comunidades y, quizás, con la persona misma?" (ARON, 1982, p.67 apud WACHTER, 2002, p.67).

\section{7 “LA REPUBLICA DEPORTIVA”: EL DEPORTE COMO FUERZA DEMOCRÁTICA PARA NUESTRA SOCIEDAD}

Siguiendo los tres principios democráticos que Miller ha encontrado en el deporte, Peter J. Arnold (2002) ha defendido que la esencia de la democracia puede dividirse en tres frases: 
a) "por la gente", es decir, que el sistema de gobierno exprese la voluntad de todos los miembros de la comunidad.

b) "para la gente", en el sentido de que se considere el mejor interés de todos.

c) "de la gente", de modo que todos los individuos, independientemente del lugar que ocupen en la sociedad, puedan participar en el gobierno.

Puede decirse que el principio general que subyace a estas tres frases es que todo ser humano es considerado como valioso, un carácter que debe ser asegurado mediante la concesión de derechos fundamentados en los valores de la libertad y la igualdad que sustentan toda sociedad democrática. Según Arnold (2002), estos valores han convertido la democracia en algo más que en una forma de gobierno, a saber, un modo de vida, y a su juicio (como ya hemos analizado a lo largo de este trabajo) tendría mucho en común con el deporte.

La síntesis del concepto de democracia que expresa el sentido político y social del deporte griego fue elaborada en la Modernidad por el Barón Pierre de Coubertin. En el pensamiento de éste, el deporte representa el modelo social de la república deportiva; es decir, un modelo ideal de democracia. En este modelo, según Coubertin, no habría privilegios ni injusticias. Los triunfos se conseguirían sólo en base al esfuerzo y el talento, teniendo un carácter temporal y limitado. Esto era lo que pretendían simbolizar las coronas de materiales vegetales y hojas de plantas de los antiguos juegos griegos, a saber: la limitación en el tiempo de todas las victorias, el carácter transeúnte de la victoria y la renovación constante de las posiciones obtenidas. Aquel que quería mantener su posición tenía que comprometerse a luchar por ser el mejor y ganar, porque nada le pertenecía por privilegio. Se seguía la máxima: "nuevas competiciones, nuevas victorias y ganadores"

Lo que convierte a las desigualdades sociales en intolerables, dice de Coubertin, no es la desigualdad misma sino la desigualdad injusta y su permanencia excesiva, las cuales son imposibles en el deporte. Esta justicia de comportamiento puede contribuir a hacer más justa a la sociedad. Evidentemente, como ha defendido Frans de Wachter (2002) (en referencia a la labor pacificadora del deporte), el hecho de que el deporte albergue principios de justicia en sí mismo, no va a realizarlos con su mera presencia, éstos no van a aparecer de forma automática como por arte de magia. Sin embargo, y esta parece ser también la propuesta de de Coubertin, el potencial que contiene el deporte si puede formar ciertas actitudes que creen un clima propicio para que un "efecto moral" de carácter positivo sea posible. Es decir, para que la justicia sea más fácilmente realizable.

Así, por ejemplo, el concepto de que "nada te pertenece por privilegio" expresado en el deporte como sistema social y político, hace de éste el símbolo de una sociedad abierta, de una sociedad dónde, a la hora de participar en el manejo de lo político, todos son iguales. Para de Coubertin, aquel que resulta vencedor en una competición deportiva, demuestra su virtud ética y sus habilidades frente a todos (dando muestras de respetar permanentemente las normas, reglas y valores del deporte, inspirando su propia vida en los principios de la filosofía olímpicodeportiva, demostrando ser el mejor y más valiente) mereciendo ser el jefe de la res publica, es decir, merece estar al cargo del gobierno y la ciudad.

El deporte, concebido de este modo, se convierte en una forma justa de democracia; un sistema formalmente justo, porque está basado en la equidad, que es algo más que la justicia, como decía Aristóteles en la Ética a Nicómaco, de distribución de los premios y las recompensas, 
y un sistema que garantiza el unicuique suum del derecho según el principio de la asignación a cada persona de sus roles y funciones sobre la base del valor personal públicamente demostrado y aceptado, que se ha expresado a través de las habilidades personales y los resultados que éstas han producido. Como ya se ha afirmado, Rawls, especialmente en Justice as Fairness (1985), utilizó las condiciones de igualdad que se encuentran en el deporte como símil y lugar de partida para esbozar su concepción de la justicia. También el filósofo italiano Antonio Gramsci, antifascista y padre espiritual de la democracia italiana, decía que los deportes, practicados con conciencia y lealtad están entre las más nobles experiencias posibles para los seres humanos ${ }^{1}$.

Por ello, autores como Arnold (2002) han propuesto que el deporte puede ser una fuerza educadora en democracia fundamental para nuestras sociedades. Siguiendo su propuesta, y contra Huzinga (2005) defenderemos que, aunque ciertamente el deporte moderno profesionalizado se haya visto desposeído de la mayoría de sus fuerzas de carácter lúdico, sin embargo, esto no quita que contenga dentro de sí muchos elementos "serios". Principios y valores que en su día fueron inspiración (y quién sabe si causas) de prácticas tan valiosas como la filosofía o la política, y que crecieron de la mano de los cultos religiosos que aportaban sentido y "encanto" (en el sentido webberiano) a la realidad social de nuestros antepasados, sobre todo, de la sociedad más propiamente deportiva: la Grecia Clásica.

\section{CONCLUSIONES: MÁS ALLÁ DE LO LÚDICO. EL DEPORTE TAMBIÉN ES SERIO}

El punto de partida de este texto ha sido la clásica discusión en filosofía del deporte que analiza si el deporte, debido a su naturaleza fundamentalmente lúdica, es una actividad trivial para la sociedad o si, por el contrario, pertenece a la esfera de lo serio. En segundo lugar, se consideró si, perteneciendo al ámbito de lo serio, el deporte tendría influencia sobre los valores y principios que rigen el global de la sociedad. Nuestra posición al respecto fue tanto que el deporte es una actividad para nada trivial, como que tiene relevancia en el global de la sociedad en lo que a valores y principios morales se refiere. Para fundamentar nuestra posición, hemos tratado de mostrar que el deporte es, en sí mismo, con su sistema ético de reglas, normas, y valores controlados por normas, un laboratorio de democracia activa, práctica y concreta, un modelo perfecto de democracia (o más bien, un modelo a miniatura de nuestra sociedad).

Evidentemente, la sola presencia del deporte en nuestra sociedad no va a promover principios y actitudes democráticas. Sin embargo, sí que podríamos modelarlo (aprovechando su especificidad) de modo que se convierta en una fuerza activa en la tarea de construir una democracia más robusta. Con esta finalidad en mente, hemos desarrollado este artículo en el que hemos mostrado que el deporte se puede concebir como una herramienta política con el potencial de desarrollar y crear un verdadero espacio para la participación, la libertad, el diálogo, y la comprensión recíproca entre las personas. Estos objetivos también pertenecen a la política como ciencia (cuya meta en crear un mundo mejor para las personas). El deporte, en definitiva, es un "gimnasio" donde las mujeres y los hombres del mundo contemporáneo pueden ejercitarse no sólo físicamente, sino también en las capacidades que les permiten hacer reales y poner en práctica los principios de la democracia, transformando el mundo en un pequeño agorá planetario donde todos somos realmente homoioi, con los mismos derechos y dignidad como seres humanos.

1 Hay que tener en cuenta que esta equidad o justicia, como se afirmó con anterioridad, debe ser complementada con otras comprensiones de la igualdad para asegurar participación universal, es decir, que todos los individuos de la sociedad sean tenidos en cuenta. Como es bien sabido, en nuestra sociedad, grupos completos de la sociedad son excluidos de la participación en el deporte (y la política), al igual que en Grecia esclavos y mujeres no tenían las mismas posibilidades de acceder al deporte que los hombres libres griegos. 


\section{REFERENCIAS}

ARON, Raymond. Confession d'un fan. L'Express, 16 April, 1982.

ARNOLD, Peter J. Democracy, Education, and Sport. En : HOLOWCHAK, Andrew M. (Ed.).

Philosophy of Sport: Critical Readings, Crucial Issues. New Jersey: Pearson, 2002.p. 484-493.

BROWN, Miller W. Paternalism, Drugs, and the Nature of Sports. Journal of the Philosophy of Sport, v.11, n. 1, p.14-22, 1984.

HOLOWCHAK, Andrew M. Moral Liberalism and the Atrophy of Sport: Autonomy, Desire, and Social Irresponsibility. En: HOLOWCHAK, Andrew M. (Ed.). Philosophy of Sport: Critical Readings, Crucial Issues. New Jersey: Pearson, 2002. p. 75-84.

HUIZINGA, Johan. Homo ludens, Madrid: Alianza, 2005.

ISIDORI, Emanuele; REID, Heather L. Filosofia dello sport, Roma: Mondadori Bruno, 2011.

KRETCHMAR, R. Scott. Dualism, dichotomies and dead ends: Limitations of analytic thinking about sport. Sport, Ethics and Philosophy, v. 1, n. 3, p.266-280, 2007.

LÓPEZ FRÍAS, Francisco Javier; GIMENO MONFORT, Xavier. The hermeneutics of sport: limits and conditions of possibility of our understanding of sport. Sport, Ethics and Philosophy, v. 10, n. 4, p.375-391, 2016.

MCNAMEE, Michael; PARRY, Jim (Eds.) Ethics and Sport. London: Routledge, 1998.

MILLER, Stephen G. The Organization and Functioning of the Olympic Games. En: PHILIPS, David J.; PRITCHARD, David. Sport and Festival in the Ancient Greek World, Swansea: Classical Press of Wales, 2003. p. 1-40.

MILLER, Stephen G. Ancient Greek Athletics, Yale: Yale University, 2004.

MORGAN, William J. Broad Internalism, Deep Conventions, Moral Entrepreneurs, and Sport. Journal of the Philosophy of Sport, v. 39, n. 1, p.65-100, 2012.

NEILS Jennifer. Goddes and Polis: The Panathenaic Festival in Ancient Athens. Princeton: Princeton University, 1992.

PAWLENKA, Claudia. The Idea of Fairness: a General Ethical Concept or One Particular to Sport Ethics, Sport, Ethics and Philosophy, v. 32, n. 1, p. 49-64, 2005.

PHILIPS, David J. Athenian Political History. A Panathenaic Perspective. En: PHILIPS, David J.; PRITCHARD, David. Sport and Festival in the Ancient Greek World. Swansea: Classical Press of Wales, 2003. p. 197-232.

RAWLS, John, Justice as Fairness: Political not Metaphysical. Philosophy and Public Affairs, v. 14, n. 3, p. 223-251, 1985.

REID, Heather L. Athletics and Philosophy in the Ancient World: Contests of Virtue. New York: Routledge, 2011.

RUSSELL, John S. Are Rules All an Umpire Has to Work With? Journal of the Philosophy of Sport, v. 26, n. 1, p. 27-49, 1999. 
SIMON, Robert L. Internalism and Internal Values in Sport. Journal of the Philosophy of Sport, v. 27, n. 1 , p. $1-16,2000$.

SIMON, Robert L. Fair Play: the Ethics of Sport. Boulder: Westview, 2010.

TUNCEL, Yunus. Agon in Nietzsche. Milwaukee: Marquette University, 2013.

WACHTER, Frans de. Education for Peace in Sport Education. En: HOLOWCHAK, Andrew M. (Ed.). Philosophy of Sport: Critical Readings, Crucial Issues. New Jersey: Pearson, 2002. p.446-454.

WEISS, Paul. Sport: a Philosophic Inquiry. Carbondale: Southern Illinois University, 1969. 
